
RHEUMATOID ARTHRITIS PATIENTS

R. Shumnalieva ${ }^{1}$, D. Kachakova ${ }^{2}$, T. Velikova ${ }^{3}$, R. Kaneva ${ }^{2}$, Z. Kolarov ${ }^{1}$ S. Monov ${ }^{1} .{ }^{1}$ Department of Internal Medicine, Clinic of rheumatology, ${ }^{2}$ Molecular Medicine Center, Department of Medical Chemistry and Biochemistry, Medical University - Sofia; ${ }^{3}$ University Hospital "Lozenetz", Sofia, Bulgaria

Background: IL-17 is a proinflammatory cytokine, which overproduction promotes the autoimmune reaction in rheumatoid arthritis (RA). Recent studies have shown that IL-17 production in lymphocytes or its function could be regulated by miR-223 by targeting Roquin ubiquitin ligase or its receptors ${ }^{1-4}$.

Objectives: To examine a possible correlation between the expression levels of miR-223 and IL-17A in peripheral blood (PB) and synovial fluid (SF) of RA patients.

Methods: Expression levels of miR-223 were determined in matched PB and SF samples of RA patients by relative quantitation method $2^{-\Delta \Delta C t}$. As reference control for normalisation RNU6B gene was used. Concentrations of IL-17A in matched serum and SF samples were determined by Human IL-17A ELISA kit (Gene probe, Diaclone). The results were compared to healthy control (HCs) as well as within the RA group.

Results: $58,73 \%$ of the RA patients showed overexpression of miR-223 in PB when compared to $\mathrm{HCs}(\mathrm{p}=0.008)$ with $\mathrm{AUC}=0.673$ (95 Cl: $0.562 / 0.784)$, with $71.4 \%$ sensitivity and $46.9 \%$ specificity $(p=0.006)$. miR-223 was overexpressed in $79.17 \%$ of RA SF $(\mathrm{p}=1.64 \times 10-3)$ when compared to HCs SF with AUC $=0.841$ (95 Cl: $0.724 / 0.958)$ with $87.5 \%$ sensitivity and $72.7 \%$ specificity $(p=4.6 \times 10-4)$. Within the RA group, SF miR-223 was underexpressed in $58.7 \%$ of the patients compared to its systemic levels. Levels of IL-17A were higher in RA SF compared to serum (8.645 $\mathrm{pg} / \mathrm{ml}$ versus $0.315 \mathrm{pg} / \mathrm{ml}, \mathrm{p}=0.012)$

Conclusions: The difference between the systemic and local levels of miR-223 and IL17A in RA patients shows that the inflammatory disease process leads to their altered expression with a possible role of both molecules in the disease pathogenesis. The opposite changes in their systemic and local levels confirm the data about the possible role of miR-223 in regulating IL-17 function.

\title{
REFERENCES:
}

[1] Haneklaus M, Gerlic M, O’Neill LA, Masters SL. miR-223: infection, inflammation and cancer. J Intern Med. 2013;274(3):215-226.

[2] Khan D, Ansar Ahmed SA. Regulation of IL-17 in autoimmune diseases by transcriptional factors and microRNAs. Front Genet. 2015;6:236.

[3] Moriya N, Shibasaki S, Karasaki M, Iwasaki T. The Impact of MicroRNA 223-3p on IL-17 Receptor D Expression in Synovial Cells. PLoS One 2017;12(1):e0169702.

[4] Schaefer J, Nakra N, Montufar-Solis D, Vigneswaran N, Klein J. Role for miR-223 and Roquin in IL-10 mediated regulation of IL-17. J Immunol 2013;190(1 Supplement):171.9.

Acknowledgements: The study was supported by Grant 14D/2012 and Grant 61/2015 funded by Medical University-Sofia, Bulgaria

Disclosure of Interest: None declared

DOI: 10.1136/annrheumdis-2018-eular.5803

\section{AB0079 ALFACALCIDOL SUPLEMENTATION MODULATES CYTOKINE PRODUCTION IN PERIPHERAL BLOOD MONONUCLEAR CELLS CULTURE OF PATIENTS WITH ACTIVE RHEUMATOID ARTHRITIS}

T. Zivanovic Radnic ${ }^{1}$, K. Simic Pasalic ${ }^{1}$, M. Sefik Bukilica ${ }^{2}$, N. Damjanov ${ }^{2}$ J. Vojinovic ${ }^{3}{ }^{1}$ Institute for Rheumatology, Belgrade; ${ }^{2}$ Institute of Rheumatology, Faculty of Medicine, University of Belgrade, Belgrade, ${ }^{3}$ Clinical Center, School of Medicine, University of Nis, Nis, Serbia

Background: Hormone D and its analogues display immunomodulatory activities that provide a beneficial effect in immunoinflammatory diseases. However, whether this hormone has an additive immunosuppressive effect when it is used with corticosteroids has not been investigated, although these agents are commonly used together.

Objectives: Testing the immunomodulatory in vitro effects of vitamin D analogue, alfacalcidol, in peripheral blood mononuclear cells (PBMC) cultures of patients with active rheumatoid arthritis (RA).

Methods: Sixteen patients with active RA were enrolled in the study. Patients PBMCs were isolated, stimulated with PMA/lonomycin and cultivated for 48 hours at $37^{\circ} \mathrm{C}, 5 \% \mathrm{CO}_{2}$ in cell cultures medium with or without supplementation. In vitro effects of supplementation with alfacalcidol (concentration

$10 \mathrm{nM}$ ), calcitriol (concentration $10 \mathrm{nM}$ ), methylprednisolone (concentration $400 \mathrm{nM}$ ) and cotreatment with alfacalcidol/methylprednisolone on cytokine production were studied. Stimulated production of cytokines IL-6, IL-17, IL-21, TNF- $\alpha$, IL-4, IL-10, TGF- $\beta$ and IFN- $\gamma$ were determined in cell culture supernatant by standard ELISA method.

Results: In vitro alfacalcidol supplementation reduces the production of proinflammatory cytokines IL-17 ( $p=0.001)$, IL-21 ( $p=0.001)$, TNF- $\alpha(p=0.002)$ and IL-6 $(p=0.4)$, and induce more intense anti-inflammatory cytokine production IL-4 $(p<0.0001)$, IFN- $\gamma(p=0.05)$, TGF- $\beta(p<0.0001)$ and IL-10 $(p=0.09)$, in PBMC cultures of patients with active RA. There was no significant difference between the effects of alfacalcidol and calcitriol, except decreased TGF- $\beta$ production $(p=0.535)$ after calcitriol supplementation. Methylprednisolone supplementation leads to a significant reduction of the IL-6 ( $p=0.002), I L-17(p=0.0001)$, TNF- $\alpha$ $(\mathrm{p}=0.0001)$ and IL-4 $(\mathrm{p}=0.017)$ production, while increased production of IL-21, IL 10 , IFN- $\gamma$ didn't reach statistical significance. Cotreatment with alfacalcidol and methylprednisolone leads to additional, more significant reduction of IL-17 $(p=0.0001)$ and TNF- $\alpha(p<0.0001)$ in PBMCs of patients with active disease.

Conclusions: Alfacalcidol, in vitro, showed a significant immunomodulatory effect through the specific inhibition of Th1- cytokine production, while Th2 cel response was enhanced - "Th2 switch". Our results demonstrate that alfacalcido has significant additive effects on glycocorticoid-mediated inhibition of Th1 cyto kine production when combined with methylprednisolone. These findings demonstrate the potential use of alfacalcidol as an immunosuppressive agent when combined with corticosteroids in Th1, but not Th2, immune response.

\section{REFERENCES}

[1] Živanović Radnić T, Simić-Pašalić K, Šefik Bukilica M, Misirlić Denčić S, Isaković AM, Stojković T, Petronijević N, Damjanov N, Vojinović J. J. Serb. Chem. Soc 2016. doi:10.2298/JSC160506039Z

[2] Cutolo M. Vitamin D and autoimmune rheumatic diseases. Rheumatology 2008.

[3] Andjelkovic Z, Vojinovic J, Pejnovic N, Popovic M, Dujic A, Mitrovic D, et al. Disease modifynig and immunoregulatory effects of high oral dose 1a (OH)D3 in rheumatoid arthritis patients. Clin Exp Rheumatol 1999;17 (4):59-62.

Disclosure of Interest: None declared DOI: 10.1136/annrheumdis-2018-eular.7550

\section{AB0080 DIFFERENTIAL EFFECTS OF TR14 VERSUS DICLOFENAC ON PRO-RESOLVING LIPID MEDIATORS REVEALED BY RNASEQ}

G. St. Laurent, III ${ }^{1}$, I. Toma ${ }^{2}$, M. Tackett ${ }^{3}$, J. Zhou ${ }^{1}$, M. Ri ${ }^{4}$, D. Shtokalo ${ }^{5}$, Y. Vyatkin ${ }^{4}$, T. Jepson ${ }^{1}$, K. Cesnulevicius ${ }^{6}$, B. Seilheimer ${ }^{6}$, T. Mccaffrey ${ }^{2} .{ }^{1}$ The St. Laurent Institute, Vancouver, WA; ${ }^{2}$ Department of Medicine/Division of Genomic Medicine, The George Washington University, Washington, $D C$; ${ }^{3}$ SeqLL, Inc., Woburn, MA, USA: ${ }^{4}$ AcademGene, LLC: ${ }^{5}$ A.P. Ershov Institute of Informatics Systems, Novosibirsk, Russian Federation; ${ }^{6}$ Biologische Heilmittel Heel GmbH, Baden-Baden, Germany

Background: Anti-inflammatory agents are used widely in treating numerous pain and inflammatory conditions. With a focus on the specialised pro-resolving mediators (SPM) pathways in cutaneous wound repair in mice, the therapeutic activities of $\operatorname{Tr} 14$ (Traumeel), a multicomponent/multitarget natural product, and diclofenac (NSAID), a non-selective cyclooxygenase (COX) inhibitor were compared. COX inhibitors can block the synthesis of prostaglandins and thromboxanes from arachidonic acid, and can have important effects on the synthesis of resolvins and protectins produced by similar enzymes from eicosopentanoic and docosohexanoic acid substrates. Differential effects were identified via transcriptome analysis (RNAseq).

Objectives: To compare the transcriptomic changes after administration of $\operatorname{Tr} 14$ or diclofenac in a mouse cutaneous wound healing model, with particular emphasis on the SPM pathways, which include resolvins and protectins.

Methods: After abrasive wounding, the wounds were treated with topical Tr14 (34 mg/ml) in combination with subcutaneous Tr14 injections $(9.5 \mathrm{mg} / \mathrm{ml})$, or with subcutaneous Tr14 injections only, or topical diclofenac at clinically relevant doses $(2 \mathrm{mg} / \mathrm{ml})$. Skin samples were analysed for RNA transcript profiling by RNAseq at specific times (12 hour, 24 hour, 36 hour, 72 hour, 96 hour, 120 hour, 192 hour) after injury. Differentially expressed genes (DEGs) were computed at each time point between diclofenac vs control or Tr14 vs control, using EdgeR.

Results: At early time points (12-36 hour), Tr14-treated wounds, and to a lesser extent diclofenac-treated wounds, showed marked induction of 3 lipoxygenase 
enzyme mRNAs involved in SPM synthesis. Even more striking was a pronounced effect of Tr14 at 12-36 hours on Fpr1 and Fpr2 mRNAs, which are the transmembrane receptors for the SPM lipid mediators. Consistent with elevated levels of enzymes regulating SPM synthesis, and SPR receptors, there was a noticeable decrease in the mRNA levels of the p65/RelA subunit of NFkB at 7296 hours. NFkB is a critical transcription factor in inflammation, regulating numerous cytokines and chemokines.

Conclusions: Tr14 and diclofenac had very different effects on the SPM synthetic pathway after cutaneous wounding. Tr14 stimulated mRNA levels of several key regulators of SPM synthesis, and had a marked effect on the mRNA levels of the SPM receptors. Tr14, not diclofenac, suppressed mRNA levels for NFkB subunit p65/RelA, which may explain some of the anti-inflammatory and proresolving properties of Tr14.

Disclosure of Interest: None declared

DOI: 10.1136/annrheumdis-2018-eular.3789

\section{AB0081 LOW LIPOCALIN-2 IN SYSTEMIC LUPUS ERYTHEMATOSUS PREGNANCIES- A POSSIBLE MECHANISM FOR LOSS OF TOLERANCE}

T.T. Pedersen ${ }^{1}$, M.H. Fenstad ${ }^{2}$, B. Jakobsen ${ }^{1}$, H.S. Koksvik ${ }^{1}$, T.S. Moksnes ${ }^{1}$, M. Wallenius ${ }^{1}$, T.H. Flo ${ }^{3}$, M. Haug ${ }^{3} .{ }^{1}$ Norwegian National Advisory Unit on Pregnancy and Rheumatic diseases; ${ }^{2}$ Dept. of Immunology and Transfusion Medicine, St. Olavs Hospital; ${ }^{3}$ Centre of Molecular Inflammation Research and Dept. of Clinical and Molecular Medicine, NTNU, Trondheim, Norway

Background: Lipocalin-2 (LCN2) has become increasingly relevant as a potential clinical biomarker of rheumatic diseases. ${ }^{1}$ The biological role of LCN2 in the adaptive immunity is less understood. It has been shown that LCN2 can induce immune tolerance by upregulation of human leukocyte antigen G (HLA-G) expression and by expansion of T-regulatory cells. ${ }^{2}$ LCN2-deficient mice have been found to be more susceptible to induction of autoimmunity. ${ }^{3}$ Systemic lupus erythematosus (SLE) is a disease associated with loss of tolerance. Pregnancy complications seen in SLE are also regarded as a consequence of immune dysregulation. LCN2 might therefore play a role as an immune modulator in SLEpregnancies.

Objectives: The study objective was to obtain a better understanding of immune regulation in pregnant women with SLE. In this study, we analysed serum LCN2 and clinical parameters in women with RA, SLE and healthy controls during pregnancy and postpartum.

Methods: The Norwegian National Advisory Unit on Pregnancy and Rheumatic Diseases collects serum samples in a biobank from women with inflammatory rheumatic diseases. Samples were obtained before pregnancy, in each trimester and 6 weeks, 6 months and 12 months postpartum from pregnant women with SLE $(n=28), R A(n=34)$ and healthy pregnant controls $(n=19)$. A sandwich ELISA was used to measure LCN2 in the serum samples. The biobank database was linked to RevNatus, a Norwegian quality registry collecting comprehensive clinical data about these women.

Results: Our cohort of pregnant women with SLE and RA had low disease activity throughout pregnancy and $67 \%-95 \%$ used medication (table 1). LCN2 levels in serum samples from women with SLE were found significantly lower compared to samples from women with RA and healthy controls at all time-points $(p<0.05)$ (graph).

Abstract AB0081 - Table 1. Disease activity and medication

\begin{tabular}{|c|c|c|c|c|c|c|}
\hline & \multicolumn{3}{|c|}{ SLE patients } & \multicolumn{3}{|c|}{ RA patients } \\
\hline & $\begin{array}{c}1 \mathrm{st} \\
\text { trimester }\end{array}$ & $\begin{array}{c}\text { 2nd } \\
\text { trimester }\end{array}$ & $\begin{array}{c}\text { 3rd } \\
\text { trimester }\end{array}$ & $\begin{array}{c}1 \mathrm{st} \\
\text { trimester }\end{array}$ & $\begin{array}{c}\text { 2nd } \\
\text { trimester }\end{array}$ & $\begin{array}{c}\text { 3rd } \\
\text { trimester }\end{array}$ \\
\hline Disease activity & & & & & & \\
\hline $\begin{array}{l}\text { LAI-P Mean (range) } \\
\text { [SD] }\end{array}$ & $\begin{array}{c}0,04(0- \\
0,25) \\
{[0,08]}\end{array}$ & $\begin{array}{c}0,02(0- \\
0,16) \\
{[0,05]}\end{array}$ & $\begin{array}{c}0,005 \\
(0-0,08) \\
{[0,02]}\end{array}$ & & & \\
\hline $\begin{array}{l}\text { DAS28 Mean } \\
\text { (range) [SD] }\end{array}$ & & & & $\begin{array}{c}2,34 \\
(1,79- \\
3,91) \\
{[0,76]}\end{array}$ & $\begin{array}{c}2,57 \\
(1,42- \\
5,02) \\
{[1,06]}\end{array}$ & $\begin{array}{c}2,57 \\
(1,79- \\
4,90) \\
{[0,94]}\end{array}$ \\
\hline Medication & & & & & & \\
\hline $\begin{array}{l}\text { Prednisolone, } \\
\text { receiving (\%) (dose } \\
\text { range }[\mathrm{mg}] \text { ) }\end{array}$ & $\begin{array}{c}17(2,5- \\
7,5)\end{array}$ & $\begin{array}{c}48(2,5- \\
7,5)\end{array}$ & $\begin{array}{c}48(2,5- \\
10)\end{array}$ & $\begin{array}{c}28(2,5- \\
10)\end{array}$ & $\begin{array}{c}33(2,5- \\
15)\end{array}$ & $\begin{array}{c}38(2,5- \\
12,5)\end{array}$ \\
\hline $\begin{array}{l}\text { Other } \\
\text { immunesupressive } \\
\text { receiving }\left(>1^{*}\right)(\%)\end{array}$ & $96(33)$ & 91 (39) & $95(43)$ & $67(11)$ & $76(5)$ & $80(10)$ \\
\hline
\end{tabular}

* $>1$ : more than one of the following: SLE: hydroxychloroquine; azathioprine, RA: sulfasalazine, methotrexate, hydroxychloroquine, TNF inhibitors

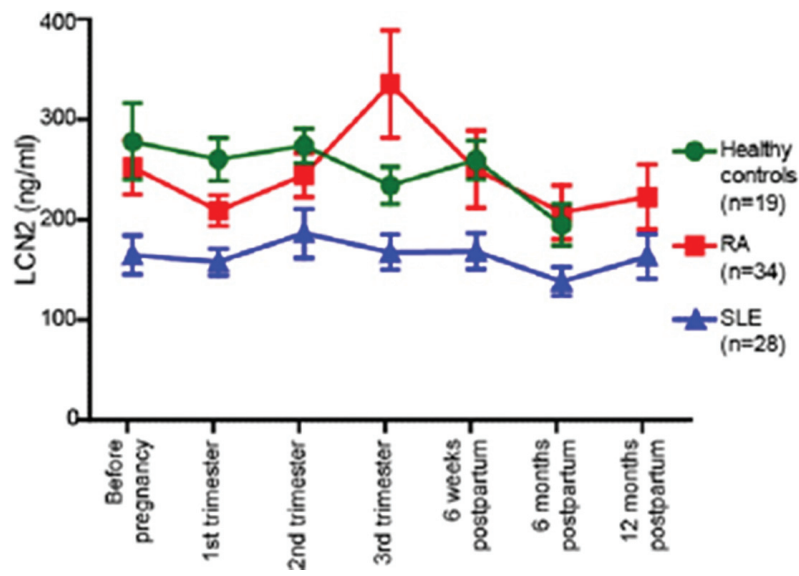

Abstract AB0081 - Figure 1

Conclusions: Pregnant women with SLE had lower levels of LCN2 compared to pregnant women with RA and healthy controls. Our cohort of women had well controlled disease, making it likely that our findings represent inherent biological differences rather than effects of disease activity. Low LCN2 levels can be a possible mechanism for loss of tolerance seen in SLE patients during pregnancy.

\section{REFERENCES:}

[1] Abella V. Biomarkers 2015;20(8):565-71.

[2] La Manna G. PLoS One 2014 Feb 27;9(2).

[3] Pawar RD. Clin Immunol 2014 Sep;154(1):49-65.

Acknowledgements: This study is supported by grants from St. Olavs Hospital and Norsk Revmatikerforbund.

Disclosure of Interest: None declared

DOI: 10.1136/annrheumdis-2018-eular.3637

\section{AB0082 CLINICALLY RELEVANT DISCREPANCIES BETWEEN DIFFERENT RHEUMATOID FACTOR ASSAYS}

W. Falkenburg ${ }^{1,2}$, H. von Richthofen ${ }^{1}$, J. Koers ${ }^{1}$, C. Weykamp ${ }^{3}$, M. Schreurs ${ }^{4}$, L. Bakker-Jonges ${ }^{5}$, I.-A. Haagen ${ }^{6}$, W. Lems ${ }^{7}$, D. Hamann ${ }^{8}$, D. van

Schaardenburg ${ }^{7}$, T. Rispens ${ }^{1} .{ }^{1} /$ mmunopathology, Sanquin Research;

${ }^{2}$ Rheumatology, Amsterdam Rheumatology and immunology Center, Amsterdam;

${ }^{3}$ Queen Beatrix Hospital, Winterswijjk, ${ }^{4}$ Erasmus MC University Medical Center,

Rotterdam; ${ }^{5}$ Reinier de Graaf Groep, Delft, ${ }^{6}$ Onze Lieve Vrouwe Gasthuis;

${ }^{7}$ Amsterdam Rheumatology and immunology Center, ${ }^{8}$ Sanquin Research,

Amsterdam, Netherlands

Background: Accurate measurements of rheumatoid factors (RFs), autoantibodies binding IgG, are important for diagnosing rheumatoid arthritis (RA) and for predicting disease course. Worldwide, various RF assays are being used that differ in technique and target antigens.

Objectives: To study whether assay choice leads to clinically important discrep ancies in RF status and level.

Methods: RF measurements using 4 commercial RF assays were compared in $32 \mathrm{RF}^{+}$samples. Using ELISAs, the influence of the target antigen source-human $\lg G$ (hlgG) versus rabbit $\lg G$ (rlgG) — on measured RF levels was investigated in arthralgia patients and RA patients.

Results: Substantial discrepancies were found between RF levels measured in the four commercial assays. 6 samples (19\%) with RF levels below or slightly above the cut-off in an rlgG-based assay were $\mathrm{RF}^{+}$in three assays using hlgG as the target antigen, some with very high levels. Direct ELISA comparisons of RF reactivity against $\mathrm{hlgG}$ and $\mathrm{rlgG}$ estimated that among $173 \mathrm{ACPA}^{+}$arthralgia patients, originally RF negative in rlgG-based assays, up to $10 \%$ were single positive against hlgG. Monoclonal RFs binding to hlgG and rlgG or hlgG only supported these findings. In a cohort of 69 early RA patients, virtually all RF responses reacted with both targets, although levels were still variable.

Conclusions: The use of RF assays that differ in technique and target antigen, together with the different specificities of RF responses, leads to discrepancies in RF status and levels. This has important consequences for patient care if RA diagnosis and disease progression assessments are based on RF test results.

Disclosure of Interest: None declared

DOI: 10.1136/annrheumdis-2018-eular.1477 